\title{
Stimulating undergraduate medical students' scientific careers: the Groningen concept
}

\author{
Johanna M. van der Wouden, Johanna Schönrock-Adema, A. Debbie C. Jaarsma
}

For many medical students entering medical school, becoming a physician-scientist is not the first career opportunity they depicted for themselves. Most students start medical school with the idea of becoming a professional medical doctor using scientific knowledge in direct patient care and in the development of protocols and guidelines. With the rapid growth of scientific knowledge and the fast development of new medical techniques and treatment options, the need for more physician-scientists is more urging then ever. However, the number of physicianscientists seem to stay behind. Gordon ${ }^{1}$ described in his review four possible reasons for this so-called "vanishing physician-scientist ${ }^{2}$ ". One of them is that students and/or residents are not dragged into science in an early stage of their career. In order to satisfy this need for more successful physician-scientists, it might be good to entice and educate undergraduate medical students in science in a very early phase of their education in order to waken interest and kindle enthusiasm for a career as physician-scientist. For this purpose, a special extracurricular program within the University of Groningen, the Junior Scientific Masterclass, was designed. The aim of this paper is to describe the Junior Scientific Masterclass against the background of the regular Groningen medical curriculum.

The aims of educating medical undergraduate students academic and scientific skills within the medical curriculum are at least two-fold. The first aim is to deliver high quality, evidence-based health care to patients and patient groups, the second aim entails to developing students' critical academic attitude and providing them with a solid basis for life-long learning 3 . In order to achieve those aims, within the Netherlands, a framework for undergraduate medical education has been developed that defines the learning outcomes of University degree Master's programs. All learning outcomes are defined in terms of competencies to ensure a Dutch physician is able to professionally perform according those minimal standards ${ }^{4}$. The framework is based on the CanMEDS ${ }^{5}$ competency model describing seven roles (medical expert, communicator, collaborator, manager, health advocate scholar and professional). As to scientific education, understanding and applying scientific knowledge in the healthcare setting as well as academic development are primarily embedded within the role of scholar (CanMEDS) ${ }^{5}$. However, depending on the context, applying scientific knowledge into practice is not solely based on the role of scholar, but also embedded in the roles of medical expert, manager and communicator.

The Groningen medical curriculum is designed according to this Dutch framework and is a patient and problem centered curriculum in which students participate within one of four learning communities. Learning within

University of Groningen and University Medical Center Groningen, The Netherlands. 
each community is, next to a common general part, based on a specific theme within the medical domain, e.g. Molecular Medicine, Global Health, Sustainable Care and Intramural Care. The focus with respect to how to apply scientific knowledge in medical care and the hands-on participation (contribute) in a small-scale scientific project in the last phase of the Bachelor is tailored to the community's specific scientific domain. Therefore, the main focus lies on applying scientific knowledge into practice and does not create the perfect breeding ground for the education of physician-scientists who also want to actively contribute to the further development of the medical field alongside patient care. In order to provide such a base, the University of Groningen developed an additional program in surplus of the regular medical curriculum.

This program - the Junior Scientific Masterclass (JSM) - has two advantages. On the one hand, it offers solid scientific education and on the other hand, such a program offers additional opportunities for those students who seek for and need more challenge than other students do. Especially excellent students have the capacities to take up extra challenge. According to the Self Determination Theory of Deci and Ryan ${ }^{7}$ individuals have three needs the need for autonomy, competence and relatedness - that have to be satisfied in order to flourish. Research provided evidence that fulfilling these three needs is indeed essential for individuals' thriving ${ }^{6,8}$. How these needs can be fulfilled may depend on the capacities of individuals. Therefore, the
JSM was founded to guide and educate the students who can handle more challenge and to offer them a program to develop their scientific skills even further. The program started, in 1999, very small, but gradually grew to an extended extracurricular bachelor honors program and MD/ $\mathrm{PhD}$ program today. The program was developed based on the notion that some medical students were intrinsically motivated to be involved in running research projects alongside their regular medical education.

As for many curricula, the JSM curriculum was thus designed with an ideal outcome in mind. According to the model of Prideaux ${ }_{9}$, curricula consist of five elements that we will use to describe the JSM program. Those five elements: outcomes or goals, content statements, teaching and learning activities, assessment strategies and context. The ideal (outcome) of the complete JSM program is to ensure that in the future more medical doctors will actively engage in scientific research (contribute to scientific knowledge, JSM) as well as take care for their patients (apply scientific knowledge, regular medical education). This ideal outcome served as a starting point for the design of the JSM program. The JSM bachelor honors program offers a wide range of courses that start in the first year, expand in the second and third years and once the student has obtained his/her bachelor degree, he or she can apply for a position to perform $\mathrm{PhD}$ research (for a schematic representation of the complete JSM program, see Figure 1).

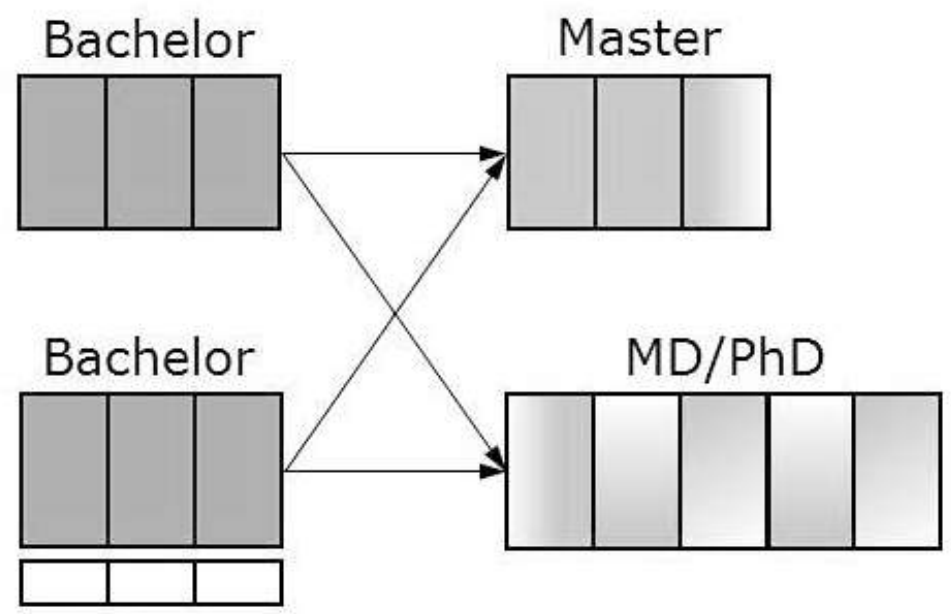

Figure 1: Schematic representation of the Groningen curriculum and the Junior Scientific Masterclass. The regular Groningen Medical curriculum consists of a Bachelor and Master Phase (upper). In addition to the bachelor program, students can attend the JSM as an additional training in scientific education (lower). During the Master phase, students can combine their regular Master with two years of PhD-research (lower) where research periods are depicted in a lighter color 
Students entering honors programs - excellent students - tend to have different learning strategies as compared to regular students ${ }^{10}$ and probably require a special educational approach that depends, for example, on course design and class interactions ${ }^{11}$. Within the Groningen medical curriculum, the Junior Scientific Masterclass can act as a breeding ground for course development where new teaching approaches and strategies can be designed and tried in practice. Within the program different teaching strategies are used eg. lecture series "from bed to bench and back", hands-on practical courses, problem-based learning strategies and a variety of other strategies. A common characteristic, except general lectures (which often are interactive), of all JSM activities is learning within small groups (4-25 students), with discussion and interaction between experts and students being embedded to enhance higher order thinking and the development of skills. Preferably, all teaching staff work within the context of combining their clinical work with active research and can serve as a role model for future physicianscientists. Depending on the individual student's needs and preferences, students can choose from the wide range of courses and subjects in such a way that the provided learning strategy and content matches the needs of an individual student at a certain time point.

After completion of the bachelor Medicine most students enter the Master Medicine, which consist of two and a half years of clinical internships and a 6 month hands-on research clerkship. In addition, the JSM MD/PhD program offers students the opportunity to combine their Master phase with a $\mathrm{PhD}$-training to obtain an $\mathrm{MD}$ and $\mathrm{PhD}$ degree upon completion. In this program, students spend an additional two years (financed) on scientific research next to their regular medical education. Students obtain their $\mathrm{PhD}$ in two years instead of the regular four years of $\mathrm{PhD}$ - research. The program features an enormous flexibility and gives students the possibility to advance specifically in their field of interest. An example outline of the program is depicted in Figure 1.

For admission to the selection procedure of the JSM $\mathrm{MD} / \mathrm{PhD}$ program, a student has to have completed prior work. This prior work has usually been done during and in addition to the regular training program during years B1 to B3 (Bachelor's program) and the Research clerkship, which should preferably be completed before the beginning of the junior clerkships (year M1). Thanks to this prior work, both the candidate and the research group have been able to gain an impression of each other's functioning, so that they can make a sound assessment of the feasibility of an entire MD/ $\mathrm{PhD}$ program. Commitment to and skills in research must then be demonstrated by a manuscript that has been offered for publication to an international journal. Since the $\mathrm{PhD}$ thesis will be based on articles, this first publication already constitutes a significant step towards the $\mathrm{PhD}$ thesis, which considerably enhances the chance of ultimate success. The JSM MD/PhD program started very small in 2001 and has grown considerably during the following years with around $35(\approx 9 \%)$ medical students entering the program in 2015 Time must tell if the desired outcome of the complete JSM program - more medical doctors actively involved within scientific research throughout their career - is reached. However, many of our students continue their scientific work during specialist training if the training environment is suitable or can be adapted in such a way that performing research is possible. For specialists in training, it should be facilitated to engage within a department's research activities to ensure that doing research alongside clinical work is not an exception, but an integral part of the training of those who strive for a career as physician-scientist.

\section{REFERENCES}

1. Gordon R. The vanishing physician scientist: a critical review and analysis. Account Res. 2012;19(2):89-113. doi: 10.1080/08989621.2012.660076.

2. Wyngaarden JB. The clinical investigator as an endangered species. New Engl J Med. 1979;301(23):1254-9. DOI: 10.1056/NEJM197912063012303.

3. De Beaufort AJ, De Goeij AFPM. Academic and scientific education in medical curricula in the Netherlands: a programme director's view. Perspect Med Educ. 2013;2:2259. doi: 10.1007/s40037-013-0076-x.

4. The 2009 Framework for Undergraduate Medical Education in the Netherlands. Utrecht: NFU; 2009.

5. The CanMEDS 2005 physician compentency framework. Better standards. Better physicians. Better care. Ottawa: Royal 
College of Physicians and Surgeons of Canada; 2005.

6. Deci EL, Ryan RM. Self-determination theory: a macrotheory of human motivation, development, and health. Can Psychol. 2008;49(3):182-5. doi: 10.1037/a0012801.

7. Ryan RM, Deci EL. Self-determination theory and the facilitation of intrinsic motivation, social development, and well-being. Am Psychol. 2000;55:68-78. doi: 10.1037/0003066X.55.1.68.

8. Vansteenkiste M, Ryan RM, Deci EL. Self-determination theory and the explanatory role of psychological needs in human well-being. In: Bruni L, Comim F, Pugno M, editors. Capabilities and happiness. Oxford, UK: Oxford University; 2008. p.187-223.
9. Prideaux D. Curriculum development in medical education: from acronyms to dynamism. Teach Teach Educ. 2007;23:294302. doi: 10.1016/j.tate.2006.12.017.

10. Kazemier E, Offringa J, Eggens L, Wolfensberger M. Motivatie, leerstrategieën en voorkeur voor doceerbenadering van honoursstudenten in het hbo. Tijdschrift voor Hoger Onderwijs. 2014;4(1):106-23. doi: 10.5553/ TvHO/016810952014032001009.

11. Scager K, Akkerman SF, Pilot A, Wubbels T. How to persuade honors students to go the extra mile: creating a challenging learning environment. High Ability Stud. 2013;24(2):115-34. doi: 10.1080/13598139.2013.841092. 